\title{
Myocardial metastasis from cervical carcinoma causing left anterior descending coronary artery occlusion and ST-segment-elevation myocardial infarction
}

\author{
Gabriel Wagman, Wilbert S. Aronow, Howard A. Cooper
}

Department of Medicine, Division of Cardiology, Westchester Medical Center/ New York Medical College, Valhalla, NY, USA

Submitted: 24 April 2015

Accepted: 25 April 2015

Arch Med Sci 2017; 13, 2: 500-503

DOI: https://doi.org/10.5114/aoms.2017.65367

Copyright $\odot 2017$ Termedia \& Banach

A 45-year-old woman with a history of squamous cell carcinoma of the cervix with metastases to the lungs presented to the emergency department with severe epigastric discomfort. An electrocardiogram (ECG) revealed sinus tachycardia with ST-segment elevation in the anterior leads (Figure 1), raising concern for acute myocardial infarction. An ECG obtained 1 year earlier had been normal. Emergent coronary angiography revealed tapering and then abrupt occlusion of the apical segment of the left anterior descending artery (Figure 2). Faint right-to-left collaterals were noted. The remainder of the coronary arteries were normal. Percutaneous coronary intervention was deferred, and the patient's symptoms resolved over the next several hours.

Serial measurements of cardiac troponins were negative. Transthoracic echocardiography revealed abnormal thickening of the apical septum and a small pericardial effusion (Figure 3). Subsequent review of a computed tomography scan of the chest obtained 3 months earlier revealed irregular, hypodense lesions within the left ventricular apex and intraventricular septum, suspicious for metastatic disease (Figure 4). Cardiac magnetic resonance imaging performed the day after admission confirmed the lesions within the left ventricular septal and apical myocardium. Left ventricular wall motion was abnormal in the regions affected by the mass, but was normal in the remaining regions. A moderate-sized pericardial effusion, bilateral pleural effusions, and multiple lung masses were also noted (Figure 5). Patient discomfort led to termination of the study prior to the administration of gadolinium. These clinical and imaging findings were felt to be most consistent with cervical carcinoma metastatic to the myocardium, resulting in occlusion of the apical segment of the left anterior descending artery by compression or direct invasion. The patient received palliative chemotherapy, and she died 2 months later. Her family declined an autopsy.

Metastatic disease of the heart, while more common than primary cardiac malignancy, is still a rare entity [1]. Autopsy studies estimate the incidence at approximately $1 \%$, although the incidence rises to approximately $10 \%$ among autopsies in which a primary malignancy is identified [2]. The 4 major modes of metastasis to the heart are: local invasion, retrograde lymphatic extension, via a transvenous route, or via hematogenous spread [1]. The most common primary tumors that result in cardiac and pericardial metastases are lung, breast, and esophageal cancers.

\author{
Corresponding author: \\ Wilbert S. Aronow MD, FACC, \\ FAHA \\ Cardiology Division \\ New York Medical College \\ Westchester Medical Center \\ Macy Pavilion, Room 138 \\ Valhalla, NY 10595 \\ Phone: (914) 493-5311 \\ Fax: (914) 235-6274 \\ E-mail: WSAronow@aol.com
}




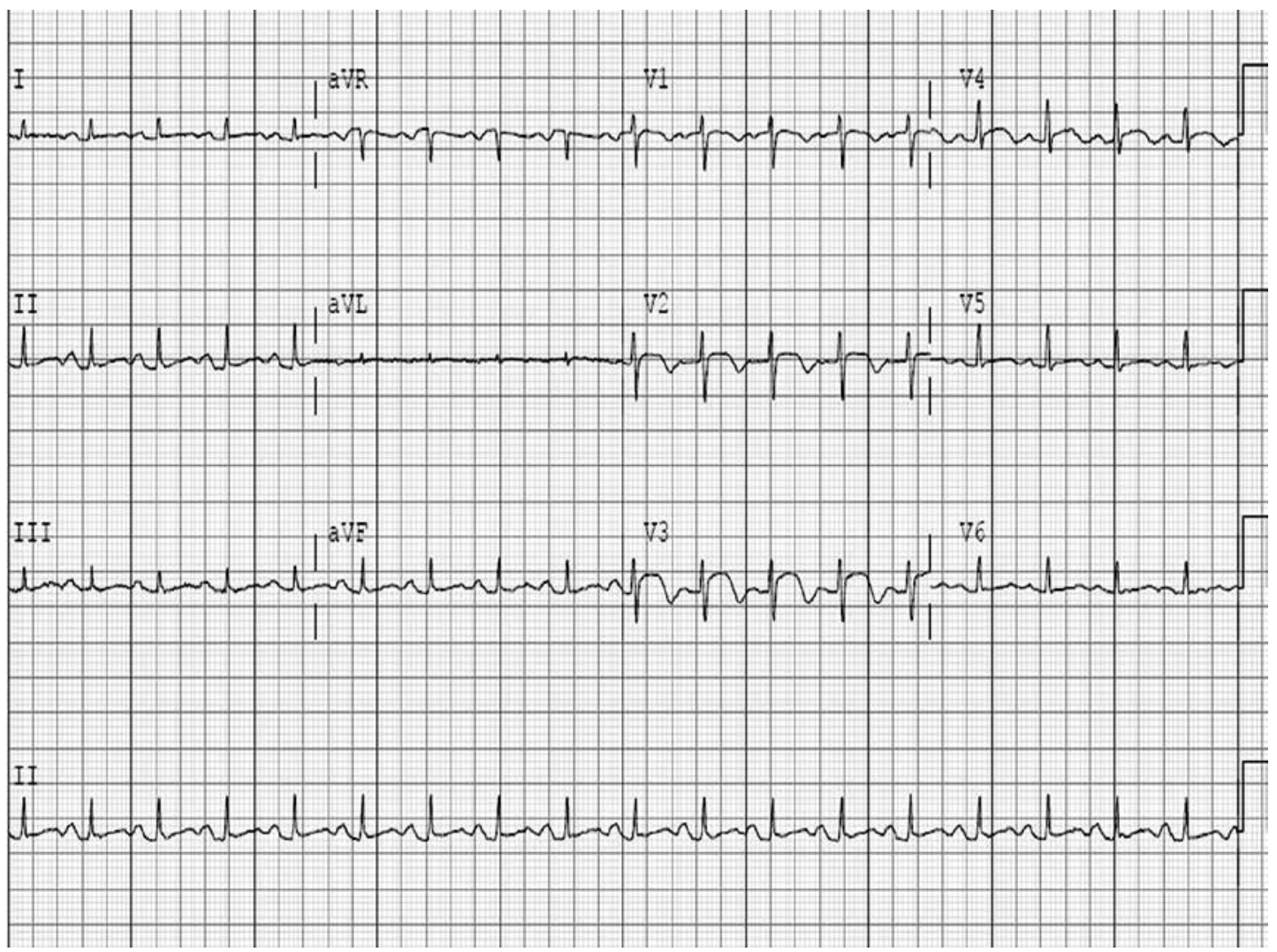

Figure 1. Electrocardiogram upon admission shows anterior ST-segment elevation
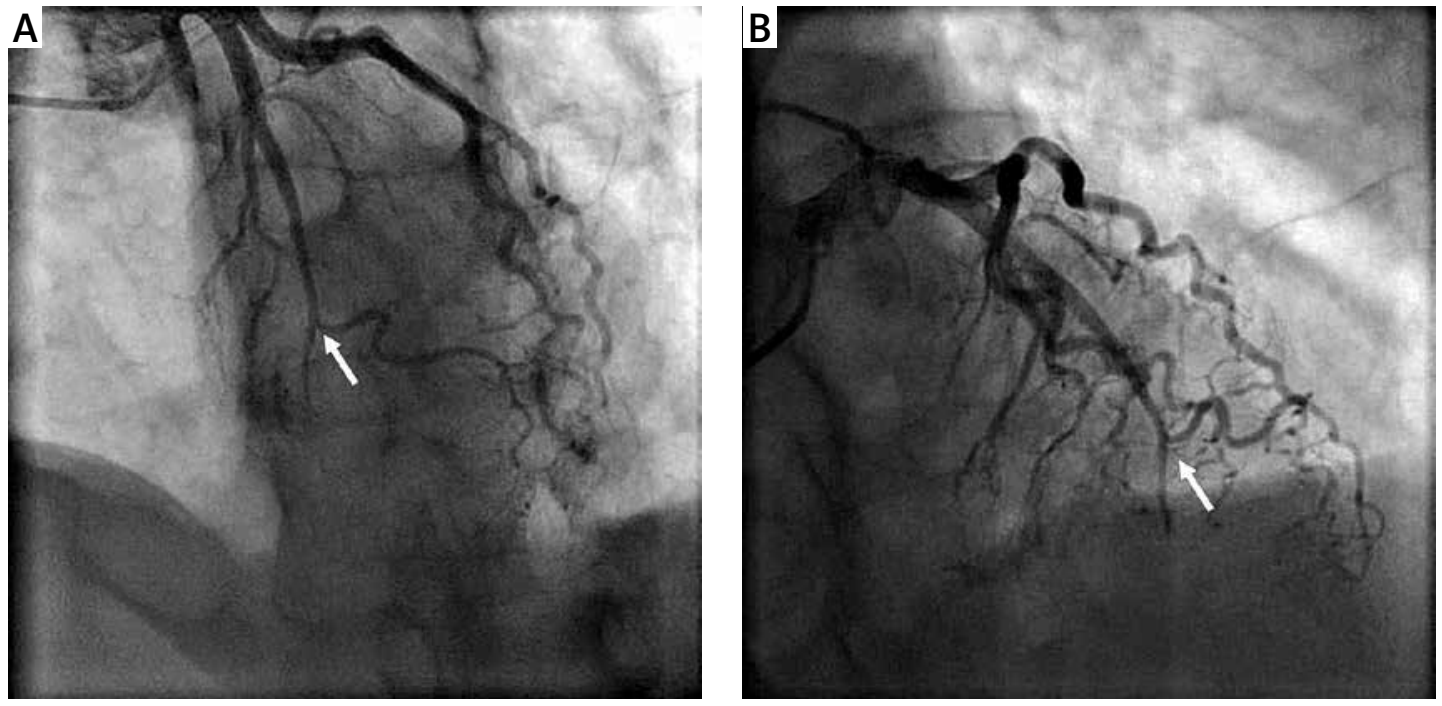

Figure 2. Coronary angiogram shows tapering and then abrupt occlusion of the apical segment of the left anterior descending artery. Anteroposterior-cranial (A) and right anterior oblique-cranial (B) images with arrows indicating the area of abrupt occlusion in the left anterior descending artery

Malignant melanoma, lymphoma, and renal cell carcinoma are less common [3].

Myocardial metastasis by cervical carcinoma is extremely rare. A review of the literature reveals fewer than a dozen reported cases. In the majority of reports, as in the current case, the cardiac lesions were discovered and characterized via a multi-modality imaging approach [4]. The current case appears to be unique among these reports in that the presentation mimicked an acute myocardial infarction, with ST-segment-elevation in the anterior precordial ECG leads. Coronary angiography demonstrated occlusion of the apical segment of the left anterior descending artery, 

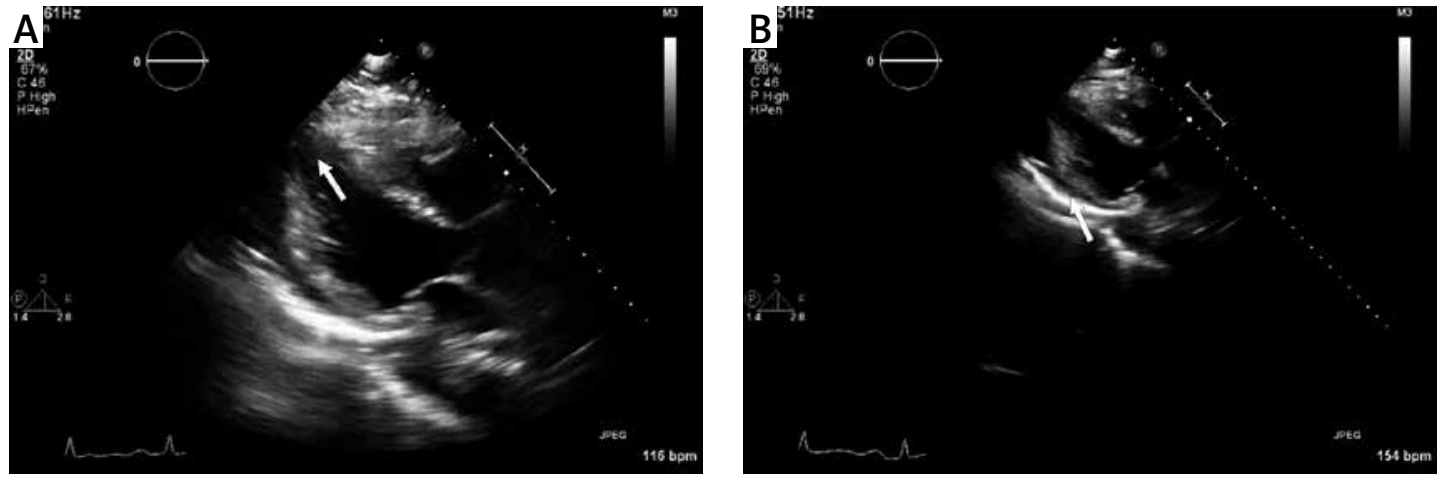

Figure 3. Transthoracic echocardiography shows abnormal thickening of the apical septum and a small pericardial effusion. Arrows indicate area of abnormal apical thickening (A) and small pericardial effusion (B)

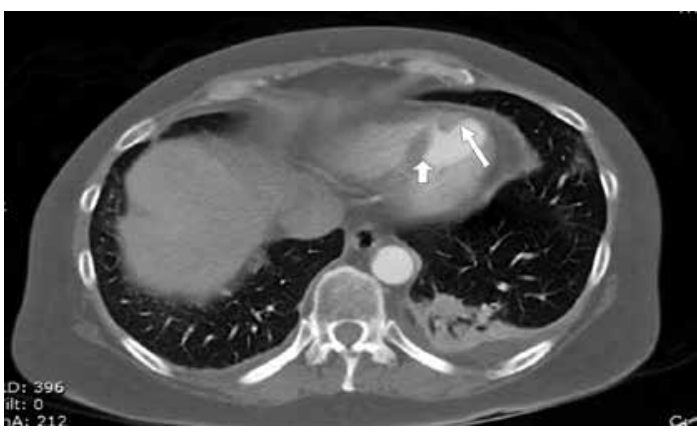

Figure 4. Computed tomography of the chest shows irregular, hypodense lesions within the left ventricular apex and intraventricular septum, suspicious for metastatic disease. Arrow indicates hypodense lesion within the left ventricular apex and arrowhead indicates hypodense lesion within the intraventricular septum

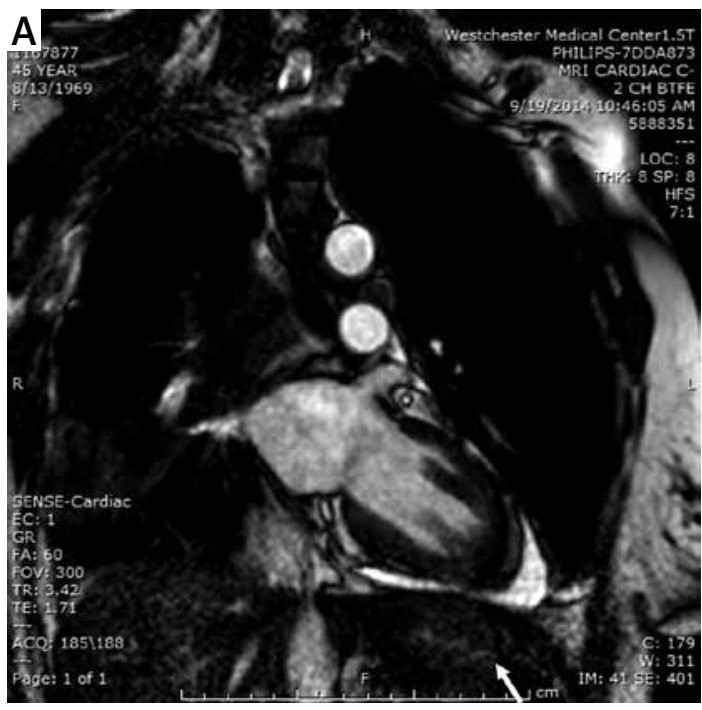

which was later determined to be due to invasion of the myocardium by tumor.

The present case is very similar, however, to a recently reported case of acute myocardial infarction due to myocardial invasion by metastases from a squamous cell carcinoma of the tongue [5]. Therefore, we suggest that in patients with known malignancies, myocardial metastases should be considered in the differential diagnosis of ischemic ECG changes and coronary occlusion. Examination of the heart using multi-modality imaging can be extremely useful in elucidating this rare diagnosis.

\section{Conflict of interest}

The authors declare no conflict of interest.

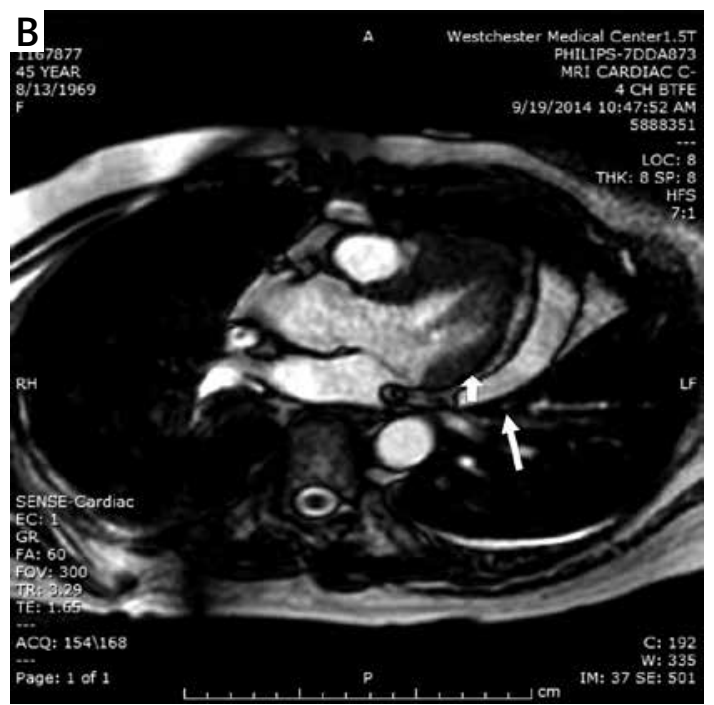

Figure 5. Cardiac magnetic resonance show lesions within the left ventricular septal and apical myocardium. Arrow indicates lesion in the apical myocardium (A) and arrow indicates lesion in the apical myocardium and arrowhead indicates lesion within the left ventricular septal myocardium (B) 


\section{References}

1. Seung WB, Sung TP, Eun YK, et al. Intracardiac metastasis from known cervical cancer: a case report and literature review. World I Surg Oncol 2013; 11: 107.

2. Chiles C, Woodard PK, Gutierrez FR, et al. Metastatic involvement of the heart and pericardium: CT and MR imaging. Radiographics 2001; 21: 439-49.

3. Goldberg AD, Blankstein R, Padera RF. Tumors metastatic to the heart. Circulation 2013; 128: 1790-4.

4. Schawkat K, Hoksch B, Schwerzmann M, et al. Diagnosis of cardiac metastasis from cervical cancer in a 33-yearold patient using multimodal imaging studies: a case report and literature review. Acta Radiol Short Rep 2014; 3: 2047981614530287.

5. Reddy G, Ahmed MI, Lloyd SG, et al. Left anterior descending coronary artery occlusion secondary to metastatic squamous cell carcinoma presenting as ST-segment-elevation myocardial infarction. Circulation 2014; 129: e652-3. 